\title{
Integrating Air-related Health Surveillance into Air Quality Management: Perceptions and Practicalities
}

\author{
C. Wright ${ }^{1}$, M.A. Oosthuizen ${ }^{2}$ and M. Steyn ${ }^{3}$
}

\begin{abstract}
${ }^{1}$ Corresponding author. Environmental Health Research Group, CSIR Natural Resources and the Environment, Pretoria, South Africa. Email: cwright@csir.co.za; Tel: +27 12841 3092; PO Box 395, Pretoria, 0001, South Africa.

${ }^{2}$ Environmental Health Research Group, CSIR Natural Resources and the Environment, Pretoria, South Africa,

Email: roosthui@csir.co.za; Tel: +27 12841 2035; PO Box 395, Pretoria, 0001, South Africa.

${ }^{3}$ Water Ecosystems and Human Health Research Group, CSIR Natural Resources and the Environment, Stellenbosch, South Africa. Email: msteyn@csir.co.za; Tel: +27 21888 2499; PO Box 320, Stellenbosch, 7599,

South Africa.
\end{abstract}

\begin{abstract}
Health surveillance is presently not an integral part of air quality management in South Africa, although ambient air pollution standards are derived from health effects of personal exposure. In a survey to air quality officials and environmental health practitioners $(n=361)$, respondents were asked to comment on a discussion document regarding ways to put health onto the air quality management agenda. Less than $7 \%$ of the sample $(n=23)$ responded, the most likely reasons being: overloaded staff; lack of knowledge about air quality-related health; and apathy. All respondents acknowledged their support of the concepts, one suggested inclusion of $\mathrm{PM}_{2.5}$ and airspora over and above criteria pollutants, and one mentioned use of an indicator 'number of complaints of visual air pollution and odour'. In general, it would appear that the links between air quality and health risks are not well understood and, more importantly, assessing airrelated health outcomes with respect to air quality is not a part of Local Municipalities' Integrated Development Plans. To motivate for necessary changes in Health Information Systems and data management, evidence of valuable application is required. Without readily available health facility and local municipality-specific data on respiratory and cardiovascular illnesses, it will prove difficult to track whether implemented air pollution mitigation measures will have positive health impacts.
\end{abstract}

\section{Keywords}

Air quality management; health; monitoring and evaluation.

\section{Introduction}

Although air pollution would not have gone unnoticed when people first succeeded in lighting a fire, they were most probably less concerned about it than they were to provide themselves with sustenance, light and warmth. The first "monitoring" of air pollution dates back to the 1920s, when scientists at Kew measured the rise and fall of the electric potential between ground level and one metre above ground (Halliday, 1978a). Maxima were detected in the mornings and late afternoons. Only years later was it realised that these changes in electric potential were due to the electric charges on particles in the air (Halliday, 1978a).

In the 1800s, people in England living close to industries producing caustic soda and sulphuric acid complained about air pollution from these industries. However, a commission of enquiry's findings said the same law protecting people's health should not deprive the workers of their livelihoods or the country of profits earned through the exportation of these chemicals. The same commission proposed emission control through the application of the "Best Practicable Means" principle, which resulted in the Alkali Act of 1863 (Halliday, 1978b). Dr Halliday, who was of the opinion that air quality management should be based on a compromise between protecting human health and the viability of industries, was involved in compiling the South African Air Pollution Prevention Act (APPA) (Act 45 of 1965) (RSA, 1965) which was based on the same principle of "Best Practicable Means'. This was the first air quality Act for South Africa. Under this Act, smoke-free zones were declared in some residential areas and dust from industries, such as from mine dumps, were addressed by rehabilitation (Halliday, 1978b). There was, however, never enforcement of ambient air quality standards under APPA as only guidelines existed. Over time, the APPA became outdated for several reasons, one being that it had inadequate compliance and enforcement mechanisms for effective implementation. In 2004, it was replaced with the National Environmental Management: Air Quality Act (Act 
No. 39 of 2004) (RSA, 2004). Where the APPA controlled pollution at source, the Air Quality Act controls pollution in the receiving environment. In December 2009, under the Air Quality Act, enforceable ambient air quality standards were published in Government Gazette Number 32186 (RSA, 2004). The success of legislation depends on its ease of implementation and enforcement (Boegman, 1978). However; it is too soon to know whether the Air Quality Act will comply with these requirements. An important positive component of the Air Quality Act Section $18(1)$ is provision for the declaration of Priority Areas. These are areas where ambient air quality standards are being, or may be, exceeded. Two such areas, i.e. the Highveld Priority Area and the Vaal Triangle Priority Area, have already been proclaimed and they will be managed to achieve and maintain compliance with the Air Quality Act ambient air quality standards.

These ambient air quality standards were derived from evidence on air pollution concentrations and human health effects. Air pollution may cause symptoms ranging from eye, nose and throat irritation (WHO, 2005), exacerbation of asthma (Peden, 2005) and reduced lung function (WHO, 2005) to cardiovascular symptoms such as high blood pressure (Brook et al., 2010) and lung cancer (Arden Pope et al., 2002). Krzyzanowski and Cohen (2008) found a statistically significant association between air pollution and mortality from respiratory and cardiovascular illnesses. A growing number of studies have shown that the largest burden of air pollution-related diseases is on developing countries where air pollution levels are also amongst the highest in the world (Romieu and Hernandez-Avila, 2003, Krzyzanowski and Cohen, 2008).

In South Africa, health surveillance is presently not an integral part of air quality management; although the technical committees that assisted in the development of the Air Quality Act ambient air quality standards used available evidence on health effects to determine these standards. For example, for benzene, the European Commission's Review was used as a decisionmaking tool (EU, 2003). Results from several epidemiological studies carried out in South Africa were also considered. For example, the Vaal Triangle Air Pollution and Health Study was a cross-sectional study conducted in the early nineteen-nineties that involved 14053 schoolchildren. The main findings of this study were that the majority (65\%) of participants suffered from upper respiratory diseases and
$29 \%$ from lower respiratory diseases (Terblanche, 1998). The Birth-to-Ten study was a cohort study by the Medical Research Council that followed 3275 children in Soweto from birth (in 1990) to ten years of age. Of the symptoms diagnosed by a doctor, ear infection (8\%), bronchitis $(5 \%)$, pneumonia $(4 \%)$ and allergies $(4 \%)$ were the most frequently reported (Mathee and Von Schirnding, 2003). This study is ongoing and is now known as the Birth-to-Twenty study, the only longitudinal study of its kind in Africa (Richter et al., 2007). Wesley and Loening (1996) conducted a 2-year follow-up study involving children under the age of 3 years suffering from pneumonia and compared them with controls that suffered from upper respiratory infection only. During the follow-up, it was found that any subsequent ill health of children who had suffered from pneumonia was not necessarily greater than that of the controls. In another study, children from Sasolburg, a polluted area in the Vaal Triangle Priority Area, were compared with children from Heilbron, Parys and Frankfort, areas with negligible air pollution. Results from the questionnaire survey showed no significant differences in the incidence of respiratory diseases between the study area and control areas. However, there was a statistically significant difference in lung functions (forced expiratory volume in one second $\left(\mathrm{FEV}_{1}\right)$ of boys in the two areas, with the boys from Sasolburg having significantly lower $\mathrm{FEV}_{1}$ than the boys from the other areas (Coetzee et. al., 1986). The Eastern Transvaal Highveld study conducted by Zwi et al. (1991) compared children from the polluted "Highveld" area with children in less polluted areas of the former eastern Transvaal (now Mpumalanga) as far as their respiratory health status was concerned. A slightly higher prevalence in respiratory symptoms, especially in chest illnesses (Odds Ratio $=1.88$ ) was found in children from the 'Highveld'. Contrary to the Sasolburg study, this study showed no significant difference in FEV 1 between the two groups (Zwi, et. al., 1991).

Epidemiological studies of this nature have both advantages and disadvantages. They provide evidence of the possible impacts of air pollution on specific communities. Disadvantages include difficulties in proving causation, sample size and cost. Population health surveillance using health-related indicators is a possible alternative. Indicators may include, for example, days absent from work due to respiratory illness; and number of patients admitted with upper respiratory tract infections. Furthermore, appropriate health data need to be routinely collected and made available to the air quality 
officers and environmental health practitioners who are responsible for the implementation of the Air Quality Act ambient air quality standards. This paper therefore describes, as a first step to find ways to track air-related health in air quality management, the comments made by South African air quality officers and environmental health practitioners on the need for and type of appropriate 'health' indicators, as well as other relevant issues.

\section{Materials and Methods}

A discussion document was prepared following informal interviews with air quality officers from the South African National Department of Environmental Affairs and environmental health practitioners from the National Department of Health. This document described ideas of how air quality officers and environmental health practitioners may go about bringing health into air quality management, given air pollution issues in South Africa, the relationship between air quality and health and suggested environmental health indicators for air pollution. The two-page document described ways in which managers of air quality might go about bringing health into an air quality management plan, including, meeting with all levels of the Department of Health and encouraging their participation in air quality management task teams; inviting local hospital and clinic healthcare staff to air quality management planning meetings and present on respiratory health trends; and find a champion for air-related health and involve them in the air quality management team. Figure 1 shows how air quality management may work together with health surveillance for holistic monitoring and evaluation. Drawing from the World Health Organization (1999) environmental health indicators for air pollution, four indicators were presented: ambient concentrations of air pollutants in urban areas; sources of indoor air pollution; childhood morbidity due to acute respiratory illness; and childhood mortality due to acute respiratory illness.

A list of email addresses of all air quality officers and environmental health practitioners was received from the Department of Environmental Affairs. The discussion document was sent as an attachment to all listed email addresses. Respondents were asked to read through the document and send via return email their comments on the document, as well as mention any relevant activities they may be undertaking in an effort to bring health into air quality management planning. Respondents were informed that survey item answers would be extracted from their response email, recorded and anonymously categorised before the email with name and email address was permanently deleted. No personal information was requested. Personal consent was assumed by agreement to complete and return the survey. The human research ethics guidelines of the CSIR Research Ethics Committee were adhered to at each stage of this project. Figure 1 on next page.

The first email survey was mailed on 28 January 2010 with a follow-up survey to non-respondents on 5 March 2010. Response emails were printed without the respondents' name or contact details to ensure anonymity and confidentiality of responses. All descriptive data, i.e. respondents' comments, were collated in EpiData Analysis V2.2.1.171 (EpiData Association, Odense Denmark, 2001-2009). Each respondent's home province was also captured using their email signature and/ or email address.

\section{Results}

The discussion document was emailed to 426 email addresses of which 65 email addresses no longer existed. The final sample size was 361 with a response rate of $6.3 \%(n=23)$. Figure 2 shows the number of respondents by Province, with the most number of respondents from Gauteng $(n=7)$ and the Eastern Cape $(n=6)$. There were no respondents from Limpopo, North West and the Free State Provinces. Figure 2 on next page.

The most frequently occurring respondents' comments were 'this is an interesting document' $(n=6)$ and 'we agree with this approach' $(n=7)$. Respondent comments (Table 1) were collated by issue and grouped into five categories: 1) capacity and support; 2) data and statistics; 3) education; 4) steps made already; and 5) concerns. The greatest number of comments ( $\mathrm{n}$ $=11$ ) pertained to data and statistics, in particular, that we need reliable, readily available air quality and air-related health data, perceived to be currently lacking in South Africa. One respondent mentioned the need to understand the public's perceptions of air-related health effects. This links to the need to raise awareness among society to curb air pollution, especially tyre burning and biomass burning. One respondent mentioned using air-related complaints as an indicator of public health and comparing these to ambient air pollution levels. 
Figure 1. Schematic diagram showing how air quality management can work together with health surveillance (black-bordered box not presently a part of air quality management plan).

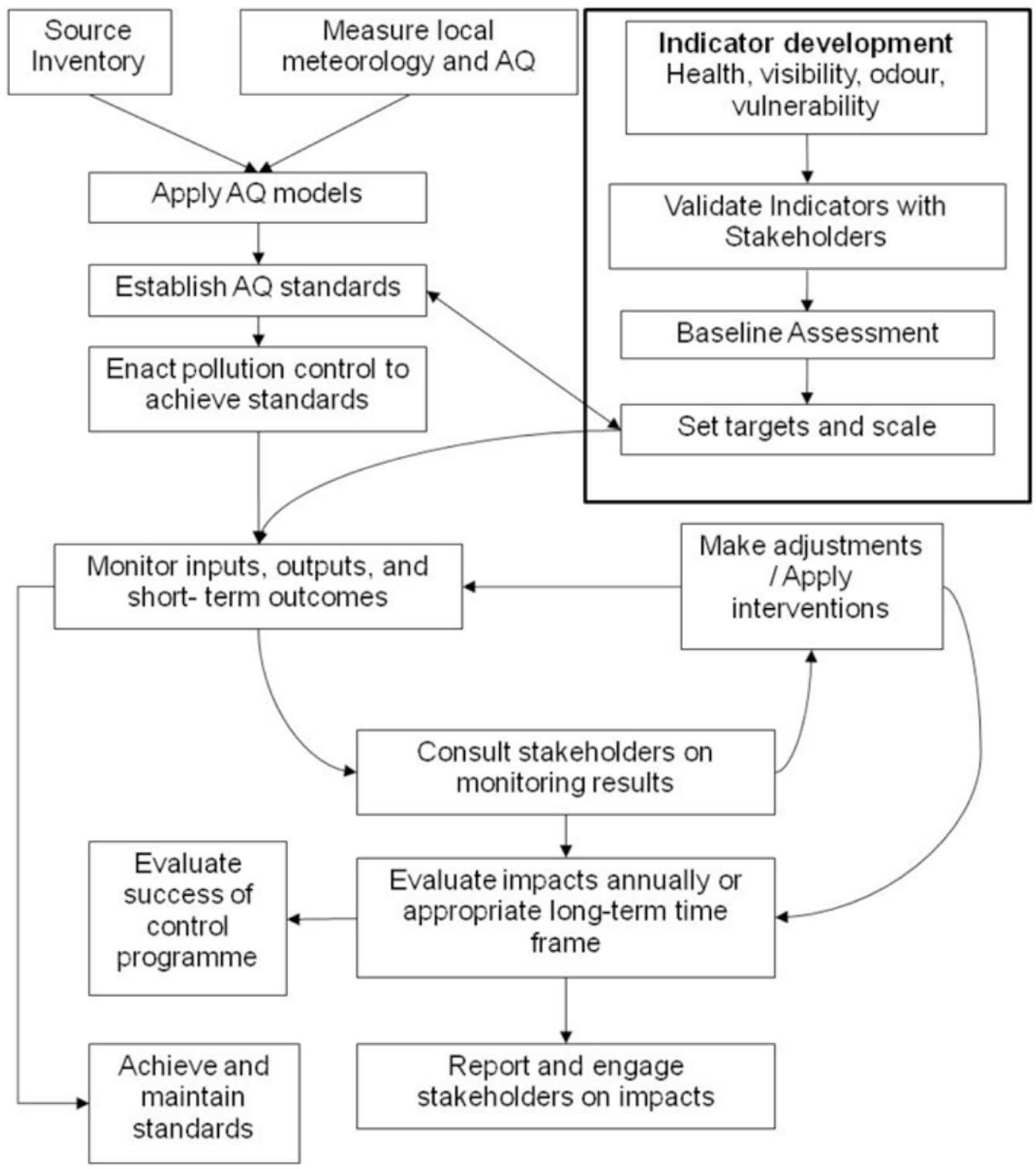

Figure 2. Percentage of respondents by Province in South Africa.

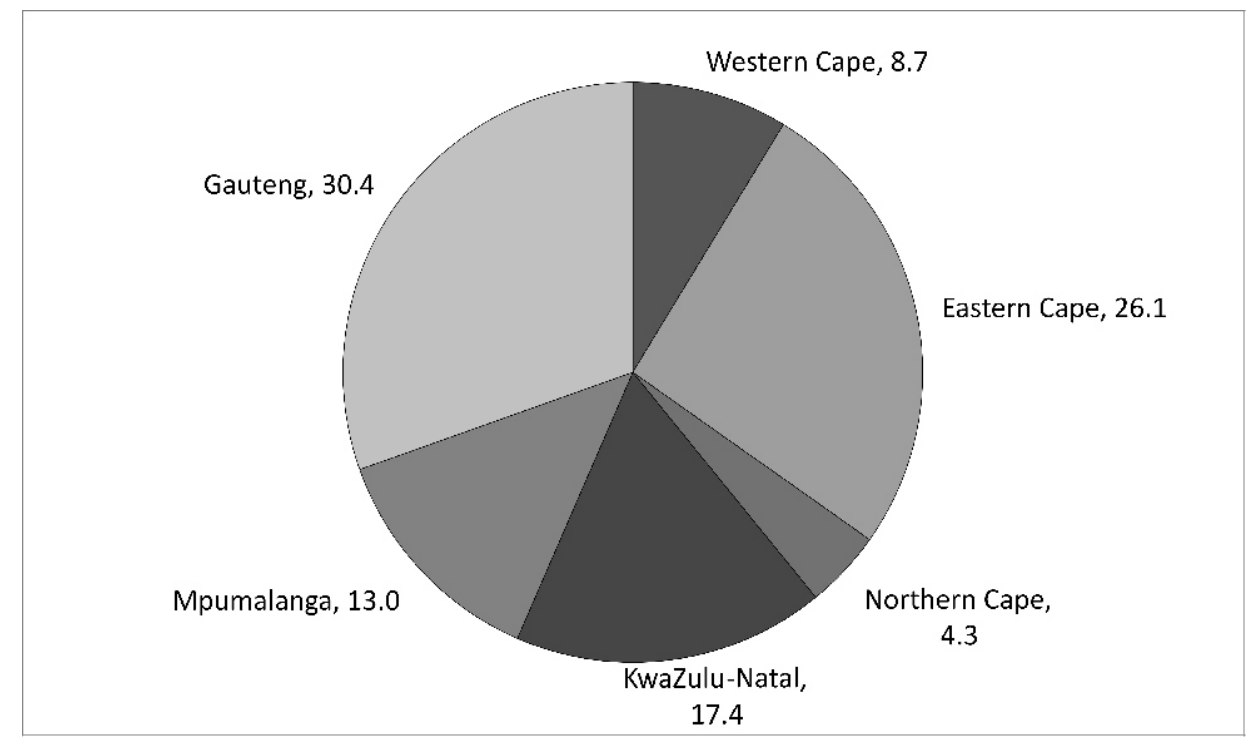


Table 1. Comments made by air quality officers and environmental health practitioners on a discussion document describing ways to put health on the agenda for air quality management

\begin{tabular}{|c|c|c|}
\hline & & Respondents' Comments (number of respondents in parentheses) \\
\hline 1 & $\begin{array}{l}\text { Capacity and } \\
\text { support }\end{array}$ & $\begin{array}{l}\text { EHPs are involved in air quality management (1) } \\
\text { EHPs and AQOs are overworked, cannot do this too (1) } \\
\text { Training is required for skilled capacity (2) } \\
\text { Lack of political support for AQMP (1) } \\
\text { Clean air as a human right should be taken as seriously as is done for water (1) } \\
\text { Health and air quality are not an integral part of Integrated Development Plans } \\
\text { (1) } \\
\text { Lack of funding to do both air quality and health improvements (1) }\end{array}$ \\
\hline 2 & $\begin{array}{l}\text { Data / } \\
\text { statistics }\end{array}$ & $\begin{array}{l}\text { We need: } \\
\text { - Reliable air quality monitoring data to be made available (2) } \\
\text { - } \text { Accurate and relevant health data to be made available (2) } \\
\text { - To determine major pollution sources per area (1) } \\
\text { - Resecument society's perceptions of air-related health effects (1) } \\
\text { - To link emission control to epidemiological studies to determine impact } \\
\text { (1) } \\
\text { - Rural and urban environmental data (1) } \\
\text { To find ways to integrate climate change into AQMP (1) }\end{array}$ \\
\hline 3 & Education & $\begin{array}{l}\text { Need to raise awareness among society to curb air pollution (1) } \\
\text { Health facility staff and management need to realise importance of capturing air- } \\
\text { related health data (2) }\end{array}$ \\
\hline 4 & $\begin{array}{l}\text { Steps already } \\
\text { taken }\end{array}$ & $\begin{array}{l}\text { Using complaints as an indicator, noticed decrease as air quality improved (1) } \\
\text { Begun exercise to compare clinical data to air quality (1) } \\
\text { Involved non-governmental organisations in AQMP annual reviews (1) }\end{array}$ \\
\hline 5 & Concerns & $\begin{array}{l}\text { Indoor air quality in informal settlements is a problem (3) } \\
\text { How to manage division of indoor (DoH), occupational (DoL) and outdoor air } \\
\text { (DEA) management ( } 2 \text { ) } \\
\text { Weighting of health indicators by population size since air quality monitoring } \\
\text { coverage is sparse (1) } \\
\text { No standard for } \mathrm{PM}_{2.5} \text { (airborne particulate matter with diameter less than } 2.5 \\
\mu \mathrm{m}) \text { in South Africa currently exists (1) }\end{array}$ \\
\hline
\end{tabular}

Note. EHP, Environmental Health Practitioner; AQMP, air quality management plan; AQO, Air Quality Officer; DoH, National Department of Health; DoL, National Department of Labour; DEA, National Department of Environmental Affairs.

Regarding capacity and support, almost all comments $(n=5)$ were emphasising the lack thereof for air quality officers and environmental health practitioners. Being overworked, undertrained and under-resourced were reasons provided by respondents. These issues may exist because of a perceived lack of understanding among management of the need for air-related health surveillance and data (education, $n=1$ ), and the disparity in the roles of air quality officers and environmental health practitioners in air quality management planning (concerns, $\mathrm{n}=1$ ).

Some air quality officers and environmental health practitioners had already taken steps to track air-related health by using complaints as an indicator $(n=1)$, comparing clinical data to air quality $(n=1)$ and involving non-governmental organisations in air quality management plan annual reviews $(n=1)$. However, as one environmental health practitioner mentioned, weighting of health indicators by population size must be considered since air quality monitoring coverage was perceived to be sparse (concerns, $n=1)$.

\section{Discussion}

International research in advancing our understanding of air quality management and ways to track air-related health outcomes is evident (Mucke, 2000; WHO, 2002; Kjellstrom, 1999; and Hurley, 2004), however, less has been done on the African continent (ICSU, 2007), 
including South Africa (Leiman et al., 2007). As new air quality legislation comes into effect, streamlining critical mass and limited resources to include health surveillance and implementation of indicators to monitor and evaluate air pollution interventions from a health perspective is imperative. This article summarises the comments of air quality officers and environmental health practitioners on means and challenges to put health on the air quality management agenda. Unfortunately, the response rate was very low. The most likely reasons for non-response were considered to be inactive email accounts; overloaded staff; lack of knowledge about air quality-related health; and apathy. Further research to elicit responses from air quality managers and improve the response rate should consider using face-to-face interviews, for example, at the annual Air Quality Lekgotla. In general, all respondents were in agreement that air-related health surveillance should be integrated into air quality management. However, several challenges were identified and are discussed here.

\section{Legislative and Policy Context}

Promulgation of the Air Quality Act introduced a positive shift in ambient air quality management in South Africa (DEAT, 2007), providing the legal and political back-up to increase the degree to which local authorities can improve, monitor and manage ambient air quality to improve human health and well-being. This new legal framework introduced a shift towards decentralisation of air quality management and, in principle, allowed for public participation. However, based on the comments received from air quality officers and environmental health practitioners, not much has changed since 2004. Even after implementation of this new legislation and policy framework, there remains a lack of political support for the development and implementation of air quality management plans as an integrated approach to Integrated Development Plans. Some environmental health practitioners commented that they were already involved in air quality management, while others felt that they simply "cannot handle these additional tasks". The feedback clearly highlighted the absence of enough skilled staff to perform these new tasks and emphasised that training and capacity building were required. This feedback was similar to comments made by Davies (2008) who suggested that a lack of resources e.g., financial, time and skills would present numerous challenges in terms of roll-out of this legislation, policy, and air quality management planning across the country. Evidently, a legal framework does not necessarily provide the political backing and buy-in needed to achieve the overarching goal.

\section{Data requirements}

The importance of relevant, reliable and readily available data is well documented (Ezzati and Kammen, 2002; Thomas et al., 2002; Strydom and King, 2009). Not surprisingly, feedback provided by the respondents clearly highlighted the need for reliable and readily available air quality monitoring data linked to accurate and relevant human health exposure and health impact data. Summary responses further suggested that in order to achieve this, it is important that the major air pollution sources are identified, modelled and mapped for both urban and rural areas throughout South Africa. More importantly, it calls for the enforcement by the various departments that data (both air quality data and human health impact data) are captured by means of a database. Such a database should allow relevant and reliable data to be readily available to all environmental health practitioners and air quality officers, nationally, to enable an immediate response to increased or decreased air pollution. The recently launched South African Air Quality Information System (www.saaqis.org.za, accessed 28 October 2010) would create an ideal platform for such a database to be incorporated into. Finally, further research is needed to identify appropriate indicators, at all levels, to ascertain human health impacts linked with air pollution reduction strategies. Indicators of ill-health related to specific air pollutants and types of emission sources are clearly needed to first assess the status quo and later to monitor and evaluate air pollution reduction strategies directly linked to human health impact.

\section{Integrated Governance}

A concern was raised by a few respondents related to the issue of a dichotomy in the roles and responsibilities of National Government line departments, specifically relating to monitoring, analysis, evaluation and reduction of indoor, outdoor as well as occupational air pollution. While this paper excludes occupational exposure to air pollution, there is a clear need for an integrated governance approach. Personal exposure to air pollution may occur outdoors, indoors at home and indoors at work. According to Chatterton et al. (2007), environmental governance works best when it is inclusive of all sectors of government and society. In order to achieve air quality management goals, adequate and transparent dissemination of information must be ensured. In addition, trust relationships, and capacity of the various departments or 
sectors within departments must be developed on a constant basis. Respondents' comments highlighted the need for an approach where focus group discussions are held with community and government stakeholders to exchange information regarding the knowledge, attitudes, practices, and beliefs of air-related health effects in order to raise awareness for the impact and causal links of air pollution and the possible impacts of air pollution interventions on quality of life.

Formal multi-stakeholder reference groups are a legislated requirement of the Air Quality Act and form part of air quality management plans. This forum would provide an opportunity to involve and invite other interested and affected parties such as stakeholders from industry, NGOs, and members of the public. It is advised that municipal clinic and hospital management are provided with an opportunity to take part in this forum. They should also be convinced of the importance of their involvement and asked to address the forum in terms of issues and concerns, but also afford the forum the opportunity to create the awareness amongst these health officials of the need for reliable and up to date health impact data.

\section{Conclusion}

All interested and affected parties should consider air quality management beyond air pollution mitigation and reduction that aims for improvement in air-related quality of life, health and extended life expectancy. This paper emphasises that comparing ambient air quality monitoring data to air-related health effects seen in the overall population is not useful. Instead, it concludes that exposure-related and specific, air-related health conditions should be identified and monitored, simultaneous to actively enforcing air-pollution reduction strategies. The current future of air pollution mitigation and improvements in air-related health in South Africa looks unclear. Drivers such as urbanisation and global climate change will increase the need for development which will likely put pressure on the quality of air. Several steps are needed to facilitate a change in mindset in all spheres of society and governance to ensure improved health, well-being and quality of life for communities.

\section{Acknowledgments}

All of the Air Quality Officers and Environmental Health Practitioners who participated in the survey are thanked for their comments. This study was funded by a CSIR Young Researchers Establishment Grant grant awarded to C Wright.

\section{References}

Arden Pope, C., Burnett, R.T., Thun, M.J., Calle, E.E., Krewski, D., Ito, K. and Thurston, G.D. (2002). Lung cancer, cardiopulmonary mortality, and long-term exposure to fine particulate air pollution. Journal of the American Medical Association 287, 1132-1141.

Boegman N. (1978). Air Quality Management or Best Practicable Means. The Clean Air Journal 4(1), 8-9.

Brook R.D., Rajagopalan S., Arden Pope III, C., Brook, J.R., Bhatnagar, A., Diez-Roux, A.V., Holguin, F., Hong, Y., Luepker, R.V., Mittleman, M.A., Peters, A., Siscovick, D., Smith Jr, S.C., Whitsel, L. and Kaufman, J.D. (2010). Particulate Matter Air Pollution and Cardiovascular Disease: An Update to the Scientific Statement from the American Heart Association. Circulation 121, 2331-2378.

Chatterton, T.J., Longhurst, J.W.S., Leksmono, N.S., Hayes, E.T. and Symons, J.K. 2007. The Importance of Enabling Integrated Governance for Environmental Management in Developing Countries - Using the South African National Framework on Air Quality as a Model [Online]. Accessed 28 October 2010.

http://www.ddrn.dk/filer/forum/File/The_Importance_of_Enablin g_Integrated_Governance_for_Environmental_Management_in _Developing_Countries.pdf

Coetzee, A.M., Smith, F.C.A., Van der Merwe, C.A., and Dreyer, R.J. (1986). Die Invloed van Lugbesoedeling op Gesondheid in die Sasolburggebied. Suid Afrikaanse Mediese Tydskrif 70, 33943.

Davies, J. (2008). Developing a Framework for Air Quality Management Plans for South African District Municipalities. MSc Thesis: Environmental Sciences, University of KwaZulu-Natal.

DEAT. (2007). The 2007 National Framework for Air Quality Management in the Republic of

South Africa. South African Government Gazette No. 30284, 11th September 2007.

European Commission (EU) (2003). Scientific Committee on Toxicity, Ecotoxicity and the Environment. Report $\mathrm{Number}$ C7/FG/csteeop/benzene/hh/12-13112003D(03), Brussels.

Ezzati, M. and Kammen, D. (2002) The health impacts of exposure to indoor air pollution from solid fuels in developing countries: knowledge, gaps, and data needs. Environmental Health Perspectives 110, 1057-1068.

Halliday, E.C. (1978a). Editorial. The Clean Air Journal 4(1), 1-1.

Halliday, E.C. (1978b). Air Pollution - Past, Present and Future. The Clean Air Journal 4(1), 3-7.

Hurley, F. (2004). Does Reducing Air Pollution Really 
Lead to Improvements in Health? A discussion note and assessment of the evidence on ex post health studies (Appendix 1). An Evaluation of the Air Quality Strategy Final Report to DEFRA, London.

ICSU. (2007). International Council for Science Regional Office for Africa: Science Plan Health and Human Well-being in Sub-Saharan Africa. ICSU ROA, Pretoria.

Kjellstrom, T. (1999). Preliminary Assessment of Potential Human Health Indicators of Air Quality. Prepared for the Environmental Indicators Programme of the Ministry for the Environment. Technical Paper No. 55 Air Quality. Auckland, New Zealand.

Krzyzanowski M. and Cohen A. (2008). Update of WHO air quality guidelines. Air Quality, Atmosphere and Health 1, 7-13.

Leiman, A., Standish, B., Boting, A. and van Zyl, H. (2007). Reducing the healthcare costs of urban air pollution: The South African experience. Journal of Environmental Management 84(1), 27-37.

Mathee, A. and Von Schirnding, Y. (2003). Air Quality and Health in Greater Johannesburg. In Air pollution \& Health in Rapidly Developing Countries, McGranahan, G. and Murray, F (eds). Earthscan, London. ISBN 185383985, pp. 209-211.

Mucke, H-G. (2000). Ambient Air Quality Programmes for Health Impact Assessment in the WHO European Region. Archives of Industrial Hygiene and Toxicology 51, 257-364.

Peden, D.B. (2005). The epidemiology and genetics of asthma risk associated with air pollution. Journal of Allergy and Clinical Immunology 115(2), 213-219.

Republic of South Africa (RSA) (1965). The Atmospheric Pollution Prevention Act (Act Number 45 of 1965). Government Printer, Pretoria.

Republic of South Africa (RSA) (2004). National Environmental Management: Air Quality Act (AQA) (Act No. 39 of 2004). Government Printer, Pretoria.

Richter, L., Norris, S., Pettifor, J., Yach, D. and Camero, N. (2007). Cohort Profile: Mandela's children: The 1990 birth to twenty study in South Africa [Online]. Accessed 28 October 2010: http://ije.oxfordjournals.org/content/36/3/504.full.pdf+ html

Romieu, I. and Hernandez-Avila, M. 2003. Air Pollution and Health in Developing Countries: A Review of Epidemiological Evidence. In Air pollution \& Health in Rapidly Developing Countries, McGranahan, G. and Murray, F (eds). Earthscan, London. ISBN 185383985, pp. 49-58.

Strydom, H.A. and King, N.D. (eds). (2009). Environmental Management in South Africa. $2^{\text {nd }}$
Edition. JUTA publishers. ISBN 978-0-7021-8134-4.

Terblanche, P. (1998). Vaal Triangle Air Pollution Health Study: Bibliography, Summary of Key Findings and Recommendations. ISBN 1-874826-89-7.

Thomas, E.P., Seager, J.R. and Mathee, A. (2002). Environmental health challenges in South Africa: policy lessons from case studies. Health \& Place 8 , 251-261.

Wesley, A.G. and Loening, W.E. (1996). Assessment and 2-year Follow-up of some Factors associated with Severity of Respiratory Infections in Early Childhood. South African Medical Journal 86(4), 3658.

WHO. (1999). Environmental Health Indicators: Framework and Methodologies. Protection of the Human Environment Occupational and Environmental Health Series. Report Number WHO/SDE/OEH/99.10. Geneva, Switzerland.

WHO. (2002). Health-related indicators of air quality. European Environment Agency / WHO Workshop Hosted by the WHO Collaborating Centre for Air Quality Management and Air Pollution Control at the Federal Environmental Agency, Berlin, 19-21 September 2002.

WHO. (2005). Air Quality Guidelines Global Update. Report Number EUR/05/5046029. Geneva, Switzerland.

Zwi, S.;., Goldman, H.I.;., Kallenbach, J.M.;., Davies, J.C.A.;., Becklake, M.R. and Reinach, S.G. (1991). Respiratory Health Status of Children in the Eastern Transvaal Highveld. The Clean Air Journal 8(3), 11 21. 